\title{
Biochemical and Genetical Studies on Ribose Catabolism in Escherichia coli $\mathrm{K} 12$
}

\author{
By ANNE ANDERSON AND R. A. COOPER \\ School of Biological Sciences, Department of Biochemistry \\ University of Leicester, Leicester, LEI $7 R H$
}

(Accepted for publication II May 1970)

SUMMARY

\begin{abstract}
A gene specifying ribokinase has been located on the Escherichia coli chromosome close to the reported position of an uncharacterized ribose*negative mutation. This uncharacterized mutant has been shown to lack ribose permease and thus the genes for two enzymes of ribose catabolism are close together on the chromosome.
\end{abstract}

\section{INTRODUCTION}

Two mutants of Escherichia coli $\mathrm{K} \mathrm{I} 2$ unable to grow on ribose as their sole carbon source have been reported in the literature (Taylor \& Trotter, I967; Anderson \& Cooper, 1969) but on the information available it was not possible to decide whether the two were biochemically identical. In this paper we show that one of them (Taylor \& Trotter, 1967) has a defect in ribose permease and that the chromosomal location of ribokinase is very close to the reported position of ribose permease.

\section{METHODS}

Bacteria. The two ribose-negative mutants used in these studies were AT 7 I 5 (Taylor \& Trotter, 1967) derived from AB 259 ( $\mathrm{HfrH}$ ) and AA 100 (formerly called R-I) (Anderson \& Cooper, I969) derived from PA $309\left(\mathrm{~F}^{-}\right)$. Strain AT 26r 4 (phoSI, ilv-I2, Sm $\left.{ }^{R}, \mathrm{~F}^{-}\right)$ was used as recipient in the phage transduction experiments.

Growth of bacteria. Bacteria were grown in liquid minimal medium or nutrient broth as described by Ashworth \& Kornberg (1966).

Uptake experiments. To measure ribose uptake, the cells were grown aerobically to mid-exponential phase (about $0.34 \mathrm{mg}$. dry wt $/ \mathrm{ml}$.) in either Oxoid nutrient broth or, to induce the enzymes of ribose catabolism, in nutrient broth supplemented with Io $\mathrm{mm}$ ribose. Organisms grown in the presence of ribose were harvested, washed with 2 vol. of nutrient broth and resuspended in nutrient broth to the original volume before use. Nutrient broth-grown cells were used directly. The cell suspension was cooled to $25^{\circ}$ and $2 \mathrm{ml}$. added to a flask containing, in $30 \mu \mathrm{l}$, , I $\mu \mathrm{Ci}$ of $\left[\mathrm{I}^{14} \mathrm{C}\right] \mathrm{ribose}$ and $0.2 \mu$ moles of ribose $\left(7.5 \times 10^{6}\right.$ c.p.m. $/ \mu$ mole ribose $)$. Samples $(0.2 \mathrm{ml}$. $)$ were withdrawn at known times and treated as described by Morgan \& Kornberg (1969) but using $\mathrm{Io} \mathrm{ml}$. of scintillation fluid.

Assay of enzymes. Cell-free extracts were prepared as described previously (Anderson \& Cooper, 1969). Ribokinase was assayed at $30^{\circ}$ by the method of Horecker (I967)

* All sugars are D-isomers unless otherwise specified. 
and protein was determined by the Folin-Ciocalteu method (Lowry, Rosebrough, Farr \& Randall, 195I) using crystalline bovine serum albumin as the standard.

Fructose 6-phosphate (F6-P) formation from ribose 5-phosphate (R 5-P) was measured in a reaction mixture containing (per ml.): $50 \mu$ moles of tris- $\mathrm{HCl}, \mathrm{pH} 7 \cdot 5$; $5 \mu$ moles of $\mathrm{MgCl}_{2} ; 0.25 \mu$ moles of NADP; $2 \mu \mathrm{g}$. of crystalline glucose 6 -phosphate dehydrogenase; $4 \mu \mathrm{g}$. of crystalline phosphoglucose isomerase; $2.5 \mu$ moles of $\mathrm{R} 5-\mathrm{P}$ and $400 \mu \mathrm{g}$. of crude bacterial protein. The change in absorbance at $340 \mathrm{~nm}$. was measured at $30^{\circ}$ on a recording spectrophotometer.

Genetic techniques. Phage PI $k c$ transduction experiments were carried out by standard techniques (Glover, 1962). The phage lysate was added to recipients (multiplicity = I) and suitable dilutions were spread on to appropriately supplemented glucose minimal medium. The transductants were streaked on to the appropriate plates to determine the inheritance of the unselected markers. To determine the inheritance of the PhoS marker, the transductants were grown aerobically for $36 \mathrm{~h}$. in nutrient broth $+0.1 \mathrm{M}$-sodium phosphate, $\mathrm{pH} \mathrm{7.5.} \mathrm{A} \mathrm{sample}(0.5 \mathrm{ml}$.) of the suspension was toluenized for $\mathrm{Io}$ min. at $37^{\circ}$ then $0.2 \mathrm{ml}$. of $0.5 \mathrm{M}$-tris- $\mathrm{HCl}$ buffer, $\mathrm{pH} 8.6$, and $0.2 \mathrm{ml}$. of $0.05 \mathrm{M}-p$-nitrophenyl-phosphate were added. After $5 \mathrm{~min}$. incubation at $37^{\circ}$ the recation was stopped by the addition of $\mathrm{I} \mathrm{ml}$. of I $\mathrm{N}-\mathrm{NaOH}$. The alkaline phosphatase constitutive ( $\mathrm{PhoS}^{-}$) transductants gave a bright yellow colour whilst the repressible $\left(\mathrm{PhoS}^{+}\right)$transductants remained colourless.

\section{RESULTS AND DISCUSSION}

Although the mutant AT 7 I 5 failed to grow on ribose as sole carbon source, it grew normally on other pentoses such as xylose and L-arabinose, and on glycolytic and gluconeogenic compounds such as glucose and lactate. This suggested that the defect in AT7I5 was in an enzyme specific to ribose catabolism. Since AT7I5 grew normally on uridine which is catabolized to yield ribose 5-phosphate (R 5-P) (Kammen, I967), it was probably in one of the enzymes which leads to the formation of internal $\mathrm{R} 5$-P from external ribose; that is, either ribose permease or ribokinase. The experiments reported here have been carried out to investigate these possibilities.

When ribose uptake by nutrient broth-grown organisms was measured, AB 259 (the parental strain of AT $\left.7 \mathrm{I}_{5}\right)$ incorporated $\left[\mathrm{I}^{-14} \mathrm{C}\right]$ ribose at a fast and constant rate, but no incorporation of radioactivity could be detected when AT7I 5 was used (Fig. I). When the organisms were grown in the presence of ribose, the rate of $\left[\mathrm{I}^{14} \mathrm{C}\right]$ ribose incorporation by $\mathrm{AB} 259$ was increased threefold but again no uptake could be detected with AT 7I 5. In contrast, a spontaneous revertant of AT7 5 which had regained the ability to grow on ribose was found to incorporate radioactivity to the same extent as did AB 259. Thus the inability of AT 7 I 5 to grow on ribose appears to be due to the absence of a functional ribose permease.

In support of the view that the AT7I5 lesion affects a ribose permease, we find that the mutant can still synthesize ribokinase. It can be seen from Table $I$ that nutrient broth-grown AT 7 I 5 contains ribokinase at about half the specific activity of its parent, $A B 259$. This ribokinase produced $\mathrm{R} 5-\mathrm{P}$ since crude extracts of $\mathrm{AT} 7 \mathrm{I} 5$ form $\mathrm{F} 6-\mathrm{P}$ as a result of the non-oxidative reactions of the pentosephosphate pathway when either R 5-P or ribose + ATP were supplied as substrate. Although growth in the presence of ribose led to an increase in the ribokinase activity of $\mathrm{AB} 259$, that of AT 715 was unchanged suggesting that external ribose could not be converted to the internal inducer 
in this mutant. Thus the ribose-negative AT 7 I 5 differs from the ribose-negative AA IOO, which is unable to grow on ribose because it lacks ribokinase (Anderson \& Cooper, 1969). This view is further supported by the observation that the ribokinase-negative mutant can take up ribose (Fig. I). The initial rate of ribose uptake by AA IOO was identical to that of its parent, PA309, but subsequently the rate decreased rapidly in the mutant whilst that of the parental strain remained constant. It is likely that this

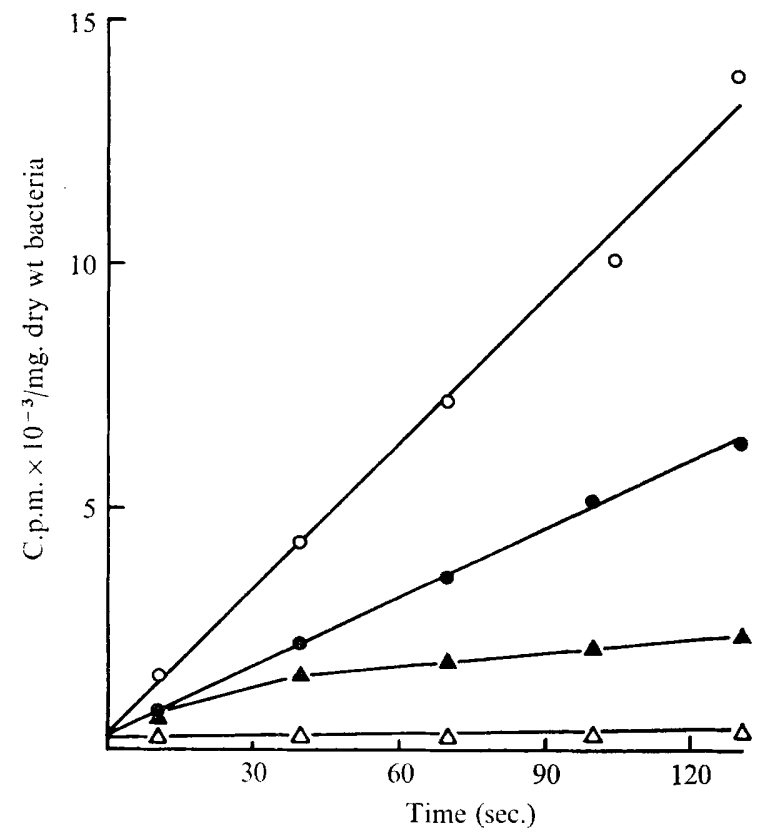

Fig. I. Accumulation of $\left[\mathrm{I}^{14} \mathrm{C}\right]$ ribose by nutrient broth-grown Escherichia coli strains AT 7I $5(\triangle)$, AA $100(\triangle)$, PA $309(\bullet)$, AB $259(\bigcirc)$. For experimental details, see text.

Table I. Ribokinase activity in $A T 715$ and $A B 259$

Ribokinase activity was measured according to Horecker (1967) as the ATP-dependent removal of ribose. The reaction mixture at $30^{\circ}$ contained in $\mathrm{I} \mathrm{ml}$.: tris-HCl buffer, $\mathrm{pH} 8.0$ (100 $\mu$ moles); $\mathrm{KCl}$ (50 $\mu$ moles); $\mathrm{MgCl}_{2}(5 \mu$ moles $) ; \mathrm{ATP}$ ( $5 \mu$ moles); Escherichia coli protein (20 to $1000 \mu \mathrm{g}$.) and ribose (I $\mu$ mole).

Growth medium

Ribose phosphorylated ( $\mu$ moles/mg. protein per min.)

Nutrient broth

Nutrient broth + ribose

$\begin{array}{cc}\text { AB 259 } & \text { AT 715 } \\ 0.038 & 0.016 \\ 0.166 & 0.018\end{array}$

Table 2. Order of the ilv, rbsK and phoS loci
P I donor...
AA IOO
AT 2614
$+$
$r b s K$
$+$

Percentage of $\mathrm{Ilv}^{+}$transductants that are:

\begin{tabular}{|c|c|c|c|}
\hline $\mathrm{Rbs}^{-} \mathrm{Pho}^{-}$ & $\mathrm{Rbs}_{20}^{-\mathrm{Pho}^{+}}$ & $\mathrm{Rbs}^{+} \mathrm{Pho}^{-}$ & $\mathrm{Rbs}^{+} \mathrm{Pho}^{+}$ \\
\hline
\end{tabular}


difference is due to the inability of AA IOO to phosphorylate the internal ribose and thereby further metabolize it. When PA309 and AAIOO were grown on nutrient broth + ribose there was a threefold increase in the rate of $\left[\mathrm{I}^{14} \mathrm{C}\right]$ ribose incorporation by PA 309 but, surprisingly, no increase for AA I00. The reason for this is not clear at the moment, but it could be that in the absence of ribokinase the organisms are unable to form the inducer for ribose permease synthesis. An alternative explanation, that the permease and kinase are functionally linked for the uptake of ribose seems unlikely, since we have other mutants which also lack ribokinase but which take up ribose very rapidly to a high level since they form ribose permease constitutively (R. A. Cooper, unpublished observations).

These results show that the two ribose-negative mutants AT7I 5 and AA 100 are biochemically distinct. Since the genetic location of the AT715 lesion, identified in the present work as ribose permease ( $r b s P$ ), is known (Taylor \& Trotter, 1967) it was of particular interest to determine the chromosomal location of the ribokinase gene $(r b s K)$ to see whether the two genes were closely linked.

Preliminary studies on the location of $r b s K$ by interruption of conjugation experiments indicated that it was close to $74 \mathrm{~min}$. on the Escherichia coli linkage map (Taylor \& Trotter, 1967) and cotransduction studies showed appreciable linkage of $r b s K$ to $i l v(73 \%)$ and a lower linkage to metE $(2.5 \%)$. The position of the $r b s K$ locus was determined more precisely by a three-factor cross infecting strain AT 26I 4 with PI $k c$ grown on the $\mathrm{Rbs}^{-}$donor. Ilv transductants were selected and subsequently analysed for the inheritance of the unselected markers $\mathrm{Rbs}^{-}$and $\mathrm{Pho}^{+}$. Among $250 \mathrm{Ilv}^{+}$ transductants $73 \%$ had inherited the $\mathrm{Rbs}^{-}$marker and $27 \%$ the $\mathrm{Pho}^{+}$marker. As Table 2 shows, the $\mathrm{Rbs}^{+} \mathrm{Pho}^{+}$recombinants were the least frequent category among the four possible phenotypes. If we assume that those transductants formed as a result of a minimum of four crossovers will occur significantly less frequently than those transductants formed as a result of a minimum of two crossovers, these results suggest that $r b s K$ is situated between $p h o S$ and $i l v$. Since $r b s P$ is also located between phoS and $i l v$, and the high linkage of $r b s K$ to $i l v(73 \%)$ is identical to the reported linkage of $r b s P$ to $i l v$ (Taylor \& Trotter, 1967 ), $r b s K$ and $r b s P$ must be very close together on the Escherichia coli chromosome.

Considering the physiological roles of ribose permease and ribokinase it seems unlikely that their close chromosomal relationship is fortuitous. It is possible that they belong to a single unit of transcription and this possibility is being investigated at the present time.

We wish to thank Professor A. L. Taylor for generously supplying the cultures of AT 7 I 5 and AB 259 used in these studies, and Professor H. L. Kornberg, F.R.S., for strain AT 26I4. A. A. is in receipt of a Studentship from the Science Research Council and this work was supported in part by grant no. B/SR/7309 from the Science Research Council.

\section{REFERENCES}

ANDerson, A. \& COOPER, R. A. (I969). The significance of ribokinase for ribose utilization by Escherichia coli. Biochimica et Biophysica Acta 177, 163-165.

Ashworth, J. M. \& KornBerg, H. L. (I966). The anaplerotic fixation of carbon dioxide by Escherichia coli. Proceedings of the Royal Society B r65, 179-188.

GLOVER, S. W. (1962). Valine-resistant mutants of Escherichia coli $\mathrm{K}$ I2. Genetical Research, Cambridge 3, 448-460. 
Horecker, B. L. (1967). Preparation and analysis of ribose-5-phosphate. In Methods of Enzymology, vol. 3, pp. 188-190. Edited by S. P. Colowick and N. O. Kaplan. New York: Academic Press.

Kammen, H. O. (1967). Nucleotide metabolism in Escherichia coli. Abstracts of the Pacific Slope Biochemistry Conference, Davis, California.

Lowry, O. H., Rosebrough, N. J., Farr, A. L. \& Randall, R. J. (I95I). Protein measurement with the Folin phenol reagent. Journal of Biological Chemistry 193, 265-275.

Morgan, M. J. \& Kornberg, H. L. (1969). Regulation of sugar accumulation by Escherichia coli. FEBS Letters 3, 53-56.

TAYLOR, A. L. \& TROTtER, C. D. (I967). Revised linkage map of Escherichia coli. Bacteriological Reviews 31, 332-353. 